\title{
Epstein-Barr virus BART microRNAs in EBV- associated Hodgkin lymphoma and gastric cancer
}

\author{
Valli De Re ${ }^{1 *} \mathbb{D}$, Laura Caggiari ${ }^{1}$, Mariangela De Zorzi ${ }^{1}$, Valentina Fanotto ${ }^{2}$, Gianmaria Miolo ${ }^{2}$, Fabio Puglisi ${ }^{2,3}$, \\ Renato Cannizzaro ${ }^{4,5}$, Vincenzo Canzonieri ${ }^{6}$, Agostino Steffan ${ }^{1}$, Piero Farruggia ${ }^{7}$, Egesta Lopci ${ }^{8}$, \\ Emanuele S. G. d'Amore ${ }^{9}$, Roberta Burnelli ${ }^{10}$, Lara Mussolin ${ }^{11}$ and Maurizio Mascarin ${ }^{12}$
}

\begin{abstract}
Background: EBV produces miRNAs with important functions in cancer growth, tumor invasion and host immune surveillance. The discovery of EBV miR-BARTs is recent, and most of their functions are still unknown. Nonetheless, some new studies underline their key roles in EBV-associated malignancies.

Main body: In EBV-associated tumors, the expression profile of miR-BARTs varies according to the cell type, autophagic process and signals received from the tumor microenvironment. By the same way of interest is the interaction between tumor cells and the tumor environment by the release of selected EBV miR-BARTs in addition to the tumor proteins trough tumor exosomes.

Conclusion: In this review, we discuss new findings regarding EBV miR-BARTs in Hodgkin lymphoma and gastric cancer. The recent discovery that miRNAs are released by exosomes, including miR-BARTs, highlights the importance of tumor and microenvironment interplay with more specific effects on the host immune response.
\end{abstract}

Keywords: EBV, Epstein-Barr virus; miRNA, Micro RNA; BART, BamHI fragment a rightward transcript, HL, Hodgkin lymphoma; GC, Gastric carcinoma cancer

\section{Background}

Epstein-Barr virus (EBV) is a double-stranded DNA virus that replicates in the human oral epithelium (lytic phase) and is transmitted by saliva. Following the primary infection, EBV persists as a latent infection in B cells and epithelial cells. About 200,000 cancer cases per year are attributed to EBV worldwide [1]. EBV is associated with many benign and malignant lymphoproliferative disorders of $\mathrm{B}$ and $\mathrm{T}$ lymphocytes and is particularly frequent in lymphomas related to congenital and iatrogenic immunodeficiencies. In addition it is sometimes

\footnotetext{
* Correspondence: vdere@cro.it

'Immunopathology and Cancer Biomarkers, Department of Translational Research, Centro di Riferimento Oncologico di Aviano (CRO), IRCCS, Aviano, $\mathrm{PN}$, Italy

Full list of author information is available at the end of the article
}

associated with carcinomas (nasopharyngeal undifferentiated carcinoma, gastric carcinoma and occasionally epithelial tumors of the lung, breast and salivary gland) and sarcoma (Inflammatory EBV-positive follicular dendritic cell sarcomas and subgroup of leiomyosarcomas in immunodeficient individuals, particularly HIV positive).

The virus enters cells by different routes. B cells are infected when the EBV envelope glycoprotein gp350 binds the Complement receptor type 2 (CR2/CD21) and the entire virus is taken up by endocytosis [2]. Epithelial cells are infected mainly by direct fusion at the cell surface where several proteins act as cofactors (e.g. ephrin receptor A2 [3], integrins [4] and nonmuscle myosin heavy chain IIA [5]; then the viral EBV capsid is released into the cell. In addition, the virus can be transmitted 
from B cells to epithelial cells and vice versa through the lytic and latent infection cycles.

The role of EBV in oncogenesis is only partially known. Multiple factors, including the EBV genome and environmental and host genetic factors, are necessary for oncogenesis. Viruses contribute to the development of human tumors by inducing cell proliferation through the abnormal activation of oncogenes or the silencing of tumor suppressors. In addition, EBV suppresses the host immune system. Virus reactivation, due to a decrease in host immune status (e.g. HIV infection, organ transplant), may favor the occurrence of EBV-associated lymphoproliferative malignancies.

During lytic infection all viral genes are expressed, while during latent infection a limited number of viral genes is expressed. The viral expression profile varies according to tumor cell type (Table 1).

In the latent form, EBV infection does not produce virions and the episome is located in the nucleus of tumor cells [6]. The latent form is favorable for EBV persistence since, by reducing viral gene expression and the expression of antigens, it helps to elude immune system. The expression of non-coding RNAs mediates immune escape rather than cellular transformation. Persistence of the viral episome requires production of the EBV nuclear antigen 1 (EBNA1) from the origin of plasmid replication Bam H1Q promoter (Fig. 1). Lytic EBV replication was thought to destroy latently infected cells and thereby inhibit tumorigenesis. However, recent studies found that initiation of the lytic cycle may also support EBV-driven malignancies. Recently, a new EBV state, intermediate between the lytic and latent forms, has been described; in this state, the expression of some lytic genes does not result in the production of effective virions [7]. The intermediate state of EBV originates from intragenic deletions that frequently occur in the BART region or in essential lytic genes (Fig. 1). The mechanisms underlying BART deletions are poorly understood. One hypothesis is that certain miR-BARTs target viral lytic proteins (e.g. BZLF1 and BRLF1) and thereby repress reactivation from latency. Wild-type EBV occasionally executes full lytic replication, leading to progeny production, but such cells are destined to die or be eliminated by the immune system. It is assumed that the intermediate state is advantageous for the virus to block reinfection of the same cells, although producing proteins and RNAs resulted in leaky expression of viral lytic genes but consented cell survival.

\section{MicroRNAs}

MicroRNAs (miRNAs) are short non-coding singlestranded RNA molecules implicated in the post- transcriptional regulation of genes via either translation repression or RNA degradation. EBV is the first human virus shown to encode miRNAs. EBV produces 25 miRNA precursors, which contain 49 mature miRNAs. EBV miRNAs are all overexpressed during latency [8]. EBV miRNAs can be transferred by secreted exosomes from infected cells. Thus, these miRNAs are potential factors for genome regulation of both infected and uninfected cells that sustain the tumor microenvironment.

miRNA precursors are clustered in two regions of the EBV genome (Fig. 1). The BamHI fragment $\mathrm{H}$ rightward open reading frame 1 (BHRF1) gene encodes three miRNA precursors (BHRF1 to 3) that generate four mature miRNAs. The BamHI fragment A rightward transcript (BART) region contains 22 miRNA precursors (BART1 to 22) that produce 44 mature miRNAs [9]. The BART region is further subdivided into subclusters 1 and 2, with the miRNAs ebv-miR-BART2-5p and ebvmiR-BART2-3p located downstream of these two clusters. Distinct EBV miRNA profiles play a crucial role in cancer by manipulating host cells. Thus, they have been proposed as markers of distinct EBV-associated tumor types and of poor prognosis.

Table 1 Protein patterns distinguishing different EBV states

\begin{tabular}{|c|c|c|c|c|c|c|c|c|c|c|c|c|c|c|c|}
\hline \multirow[t]{2}{*}{ Cell type } & \multirow[t]{2}{*}{ EBV state } & \multirow[t]{2}{*}{ BZLF1 } & \multirow[t]{2}{*}{ BARF-1 ${ }^{a}$} & \multirow{2}{*}{$\begin{array}{l}\text { miR- } \\
\text { BARTs }\end{array}$} & \multirow{2}{*}{$\begin{array}{l}\text { miR- } \\
\text { BHRF1s }\end{array}$} & \multicolumn{4}{|c|}{ EBNA proteins } & \multirow[b]{2}{*}{$3 C$} & \multirow[b]{2}{*}{ LP } & \multicolumn{2}{|c|}{ LMP } & \multirow[b]{2}{*}{$2 B$} & \multirow[b]{2}{*}{ EBER } \\
\hline & & & & & & 1 & 2 & $3 \mathrm{~A}$ & $3 B$ & & & 1 & $2 \mathrm{~A}$ & & \\
\hline Plasma cell & Lytic & + & + & + & $+\#$ & - & - & - & - & - & - & - & - & - & + \\
\hline \multicolumn{16}{|l|}{ PEL, NPC } \\
\hline Memory B cell & Latency 1 & - & - & + & $-/+$ & + & - & - & - & - & - & - & - & - & + \\
\hline Germinal center B & Latency 2 & - & - & + & $-/+$ & + & - & - & - & - & + & + & + & + & + \\
\hline \multicolumn{16}{|l|}{ cell, HD, NPC, BL } \\
\hline Naïve B cell, LCBL & Latency 3 & - & - & + & + & + & + & + & + & + & + & + & + & + & + \\
\hline Gastric carcinoma & Latency 1-2 & - & + & + & - & + & - & - & - & - & + & - & + & + & + \\
\hline
\end{tabular}

${ }^{a}$ BARF1 promoter is cell-type specific: in viral latency, BARF1 is exclusively expressed in epithelial tumors such as nasopharyngeal and gastric carcinoma but not in lymphoma. \# miR-BHRF1s are restricted to lymphoblastoid cell lines (LCL) and nasal NK/T cell lymphoma. BARF and EBER, RNA; BL Burkitt lymphoma, DLCBL Diffuse large B-cell lymphoma; EBNA EBV nuclear antigen; HD Hodgkin disease; LMP Latent membrane proteins; NPC Nasopharyngeal carcinoma; PEL Reactivity of peripheral blood lymphocytes 


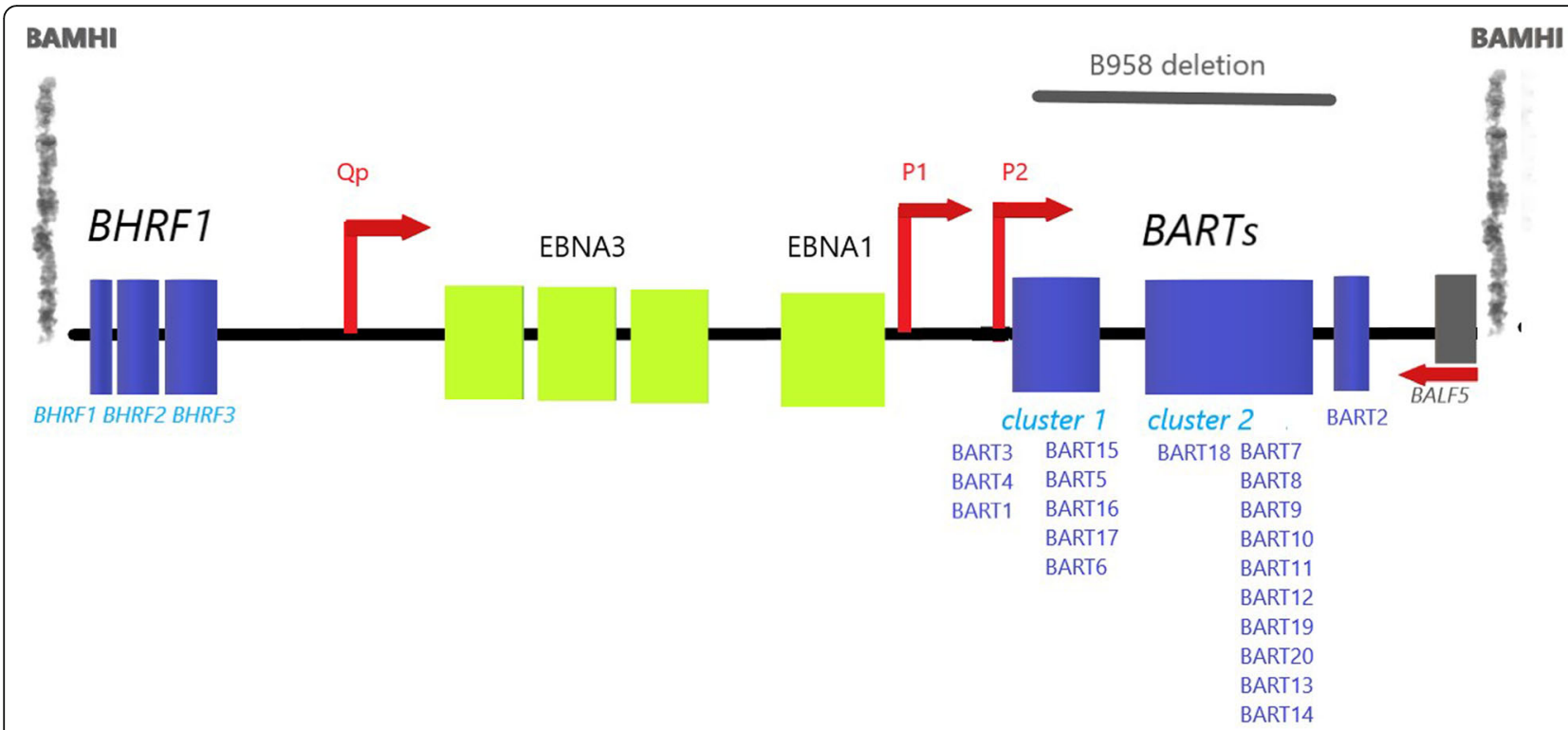

Fig. 1 Genomic map of the EBV region containing the BAMHI-I fragment. miR-BamHI fragment H rightward open reading frame 1 (BHFR1), latent EBV-encoded nuclear antigen 3 (EBNA3), latent EBV-encoded nuclear antigen 1 (EBNA1), miR-BamHI A rightward transcripts (BARTs) in sequence order. Genomic deletion in the EBV B958.9 strain is shown. P1, promoter 1; P2, promoter 2; Qp, Q promoter are indicated by arrows

\section{BART miRNAs and Inc}

Regulatory RNAs are distinguished, by sequence length, into small regulatory RNAs ( $<100$ nucleotides) and long noncoding (lnc) RNAs (> 200 nucleotides). Both miRBARTs and lnc-BARTs are expressed at high levels in $\mathrm{EBV}+$ malignancies, suggesting they have a role in tumorigenesis [10]. miR-BARTs have been mostly studied in nasopharyngeal cancer (NPC). In this cancer, they contribute to virus latency, cell proliferation and apoptosis, metastasis and tumor recurrence, and participate in the regulation of tumor cell metabolism and immune evasion [11]. Alternative splicing of BARTs results in multiple spliced forms of Lnc-BARTs, with putative open reading frames: BARF0, RK- BARF0, RPMS1, and A73 [12]. They did not produce proteins and are believed to regulate cell growth by modulating host gene expression. The mechanism is not yet elucidating. However, since lnc-BARTs localize in the nucleus, some evidence resulting from studies on BART RNAs in NPC, suggest that lnc-BARTs could mediate epigenetic regulation of gene expression by interacting with DNA methylation and the chromatin remodelling machinery [13]. Lnc-BARTs was found to control Polymerase (Pol II) at the promoter region and regulate interferon (IFN)-beta1 and chemokine-8 (CXCL8) expression in NPC [10]. However, continued investigations are still required to fully characterize the role of lnc-BARTs but it strongly possible that EBV adopt a strategy to express abundant levels of lnc-BARTs to suppress most antigenic latency EBV proteins, thus reducing host immune response in EBV-associated malignancies where only EBNA1 was found expressed.
In addition to the spliced BARTs, several EBV-encoded miR-BARTs are also encoded by the intronic regions of the BARTs. The biogenesis of miR-BARTs has been studied by Kim and Lee [14], who identified several promoters. The P1 promoter is the predominant start site. However, transcripts containing upstream sequences have been identified, suggesting that there are multiple start sites (Fig. 1). The promoter regions are possibly regulated by SP1, Ets transcription factor, Jun family members, IRF (interferon regulatory factor) proteins, c-myc, and C/EBP proteins. The transcription through exon 1 and protection from methylation around this region suggest that this region is the active template for miRNA sequences downstream of exon 1. A study has suggested that miR-BARTs are mainly transcribed by RNA polymerase II and undergo processing to be transported from the nucleus and cut at the state of pre-miRNAs by enzymes like RNAse III "Drosha" and endoribonuclease Dicer, similarly as happens for cellular miRNAs [14]. It is not yet known how BART promoters are regulated to maintain the high level of expression of BARTs seen in NPC and cancer.

Due to this important function, BARTs were proposed as biomarkers and targets of therapy in NPC. Here, we summarize the roles of the most important miR-BARTs, based on both their functions and their association with distinct EBV-associated malignancies, in Hodgkin lymphoma and gastric cancer.

\section{BART miRNAs in Hodgkin lymphoma}

In Hodgkin's lymphoma, there are very few cancer cells, and these are immersed in a microenvironment 
particularly rich in immune cells, which constitute the inflammatory niche necessary for the tumor growth and survival. The prognostic significance of EBV in Hodgkin lymphoma is controversial, however some studies indicate that a poorer outcome may be related to the age of the patients and is worse in those over 50 years. Since in the elderly the immune response is less efficient than in young people, this observation had reinforced the importance of the host immune response in the control of EBV+ Hodgkin lymphoma $[15,16]$.

Hodgkin lymphoma, like NPC and NK/T cell lymphoma, shows a latency II type, which is characterized by the expression of EBNA-1, LMP-1, LMP-2A, and LMP2B. While the EBV latent proteins have been investigated intensively in Hodgkin lymphoma, the roles of EBV miRNAs are just starting to be explored. Data so far indicate that EBV-associated tumors upregulate a subset of miR-BARTs that are silenced in latently normal infected cells in vivo [17]. It is not yet known how miR-BART expression levels are regulated. A possible mechanism is that the stability of miRNAs depends on the presence of their target mRNA in the cell.

Recently, lnc-BARTs expression was found to be regulated by NF- $\mathrm{kB}$ signaling in the induction of EBV lytic replication [18, 19]. Persistent NF- $\mathrm{kB}$ activation, is a hallmark of the malignant Hodgkin and Reed-sternberg (HRS) cells [20, 21]. The latent LMP1 gene of EBV, expressed in Hodgkin lymphoma, mimic a constitutive activation of the CD40 receptor and thereby actives NF$\kappa \mathrm{B}$ rescuing germinal center $\mathrm{B}$-cell with inefficient immunoglobulin variable (IgV) sequences from apoptosis [22]. By the same way NF- $\mathrm{kB}$ activation leads to the production and release of a large quantity of proinflammatory cytokines in the tumor microenvironment and increases the lncBARTs expression (i.e mostly RPMS1 lnc-BART [19]) that sustain either HL growth and EBV latency.

A study that investigated miR-BARTs in Hodgkin lymphoma found the expression of miR-BARTs 19-3p and 13-3p, but the overall miR-BART expression was low compared to other malignancies [23].

Plasma BART19-3p is the most significant miRNA marker for NPC diagnosis [24, 25]. It is highly expressed in tumors, with a latency III like the NK/T-cell lymphoma [26]. Today, the role of BART19-3p is not understood.

Of interest, recent studies showed that tumor cells, including EBV + Hodgkin lymphoma cells, secrete exosomes [27, 28]. Exosomes from Hodgkin lymphoma are taken up by macrophages (CD68+ cells). Tumorassociated macrophages (TAMs) have an important role in the progression of Hodgkin lymphoma. They are a major immune component of the tumor microenvironment and a good prognostic biomarker for disease-free survival and overall survival. TAMs are involved in various aspects of tumor progression including aberrant cytokine secretion, a driver of immune checkpoint blockade particularly important in Hodgkin lymphoma where the PD-L1 gene is amplified in tumor cells [29]. TAMs are also important in tumor matrix remodeling, angiogenesis, and resistance to treatment [30].

Macrophages are versatile cells capable of adapting to the signals present in the tumor microenvironment leading to different states of activation (M1, M2 and M2like) with distinct sets of surface receptors and effector molecules. M1 and M2 states depend on the main cellular sources of IFN- $\gamma$ (M1, enhances microbial killing and increases cytokine production) and IL-4 (M2, fundamental to limit tissue damage caused by inflammation). There is an association between a high infiltration of M2 macrophages (CD163+) in Hodgkin lymphoma tissue and worse disease outcome.

Exosomes are composed of a lipid bilayer with a diameter of 50-200 $\mathrm{nm}$ and they transport biological molecules. Only exosomes derived from EBV-positive Akata cell line, but not those from EBV-positive B95-8 cell line having a deletion in BART cluster 2 region (Figure 1), caused severe lymphoproliferative diseases in a humanized mouse model [27]. These results emphasize the role of BARTs in lymphomagenesis. The levels of both M1 $(\mathrm{CD} 68+)$ and M2 (CD163+) macrophages in the spleen of mice infected with Akata are higher than in mice B95-8-infected. Macrophages recognize phosphatidylserine, also known as the "eat-me" signal, exposed by both apoptotic bodies of lymphoma- derived exosomes and exosomes, and the uptake of miR- BARTs from exosomes causes macrophage phenotypic changes (e.g. increased survival and increased production of cytokines such as pro-inflammatory tumor necrosis factor (TNF)- $\alpha$ and immunosuppressive IL-10). Thus, miR-BART regulates gene expression in macrophages and directs macrophages towards a pro-tumor inflammatory state and a reduced direct host-defense against EBV.

miR-BART13-3p is the most frequent miR-BART in Hodgkin lymphoma, and it is released into the circulation via exosomes $[23,31]$. In NPC, EBV-miRBART13-3p enhanced the migration of tumor cells and caused metastasis by driving an epithelialmesenchymal transition via downregulation of the tumor suppressor AB12 [32].

miR-BART13-3p has a superior diagnostic performance than anti-EBNA1 IgA serology and EBV DNA load for NPC compared to asymptomatic EBV-infection (i.e. healthy donors and non-NPC tumors, EBV-associated diseases) [31].

miR-BART2-5p, an anti-sense miRNA to EBV DNA polymerase BALF5, was found in EBV+ Hodgkin lymphoma cells and in macrophages [33]. This finding suggests 
that miR-BARTs, through exosomes, have a role in Hodgkin lymphoma. Notably, miR-BART2-5p inhibited B-cell receptor (BCR)-mediated NF-kB activation and was upregulated during the lytic phase [34]. As a result, the level of BALF5 protein was reduced as well as the amount of virus released from EBV-infected cells, suggesting that it protects latent cells from EBV reactivation $[35,36]$. miR-BART2-5p is abundant in the circulation of patients with $\mathrm{EBV}+$ nasal natural killer lymphoma and NPC, so in both these cancers it is a diagnostic and prognostic biomarker [32, 37]. miR-BART2- 5p targets MHC class I polypeptide-related sequence B (MICB) to evade recognition and attack by NK cells [38]. MICA and MICB are ligands of the NKG2D receptor, which plays an important role in the immune response by activating NK and T cells. NKG2D was detected in about $38 \%$ of NK-cell neoplasms and cytotoxic T-lymphocytederived lymphomas [39]. MIC expression is restricted to endothelial cells, fibroblasts, epithelial cells, and tumor cells. Since NK cells efficiently recognize and kill tumor cells bearing NKG2D ligands, a reduction of MICB on the tumor surface potentially inhibits the "danger signals" that alerts the innate immune system, and therefore reduces tumor elimination.

\section{BART miRNAs in gastric cancer}

$\mathrm{EBV}+$ gastric cancer represents about $10 \%$ of all gastric cancer cases. EBV+ gastric cancer predominates in young men and localizes mainly in the proximal region of the stomach [40]. It is molecularly characterized by extreme CpG hypermethylation, frequent mutations in PIK3CA and ARID1A, lack of TP53 mutations [41, 42], and overexpression of IFN- $\square$ [43] and PD-L1 [44].

Deregulation of the NF- $\mathrm{kB}$ signaling cascade is also view as a pro-inflammatory-pathway that induce carcinogenesis, either in lymphoid cells (e.g. Hodgkin lymphoma) and in epithelial tumors (e.g. gastric cancer) [45].

In EBV-infected GC, 99\% of all virally derived polyadenylated transcripts are from BARTs, resulting in the production of miR-BARTs and lnc-BARTs [46]. They were more abundant in epithelial tumor cells than in lymphoid cells [47].

EBV latent form expressing EBER, EBNA1 and miRBARTs has been detected in EBV+ gastric cancer [47]. Latent protein LMP2A has also been detected in some cases, while LMP1 and LMP2 are often absent in noninvasive EBV+ gastric cancer [48, 49]. Almost all EBV+ gastric cancers express high levels of nearly all miRBARTs, while NPC and GC did not express miR-BHRF1 [50]. EBV miR-BARTs have been reported to regulate the expression of viral genes BZLF1 and BRLF1, to reduce both the lytic replication of the virus [51] and the oncogenic latent protein LMP1 [52].
Therefore, they regulate the viral cycle and the oncogenic transformation of gastric cells. Of note, miR-BARTs are highly expressed ( $>10 \%$ of the total pool of miRNAs) in EBV+ gastric tumor cells [53]. However, it is important to pay attention to the effects of the tumor milieu, which produces potent inflammatory mediators such as IFN- $\gamma$ that upregulate the transcription of mRNA targets, leading to differences in expression of mRNAs between gastric cancer cell lines and tissue samples [54]. EBV-positive gastric cancer tissue samples had intact MHC-I antigen presentation, including EBV antigen presentation, and increased $\mathrm{T}$-cell infiltration than EBV-negative gastric cancer tumor samples [54]. These findings may explain the better outcome of patients with EBV+ gastric cancer than with other types of this tumor [55].

The miR-BART expression profiles of clinical samples of EBV+ gastric cancer have been reported [56]. In that study, miR-BART7-3p had the highest expression level, followed by miR-BART9-3p, miR-BART1-3p, miRBART5-5p, miR-BART14-3p, miR-BART10-3p, miRBART4-5p, miR-BART1-5p, miR-BART2-5p, and miRBART15. Low expression was reported for miR-BART23p, miR-BART7-5p, miR-BART9-5p, miR-BART10-5p, miR-BART14-5p, miR-BART18-3p, miR-BART20-5p, and miR-BART20-3p. According to an in-silico analysis, this expression profile associated with oncogenesis, cell adhesion, signal transduction, and apoptosis, all of which are essential for the development and progression of gastric cancer. However, since the discovery of miR-BARTs is relatively recent, the functions of most miR-BARTs in gastric cancer pathogenesis are only beginning to emerge. A list of these miRNAs with their main functions are reported in Table 2.

The low apoptotic status of EBV-positive gastric cancer tissue, compared to EBV-negative tissue, has been associated with the effect of miR-BART4-5p on the expression of the pro-apoptotic $\mathrm{BH} 3$ interacting-domain death agonist (Bid) [56]. The function of the proapoptotic Bid gene is to mediate, by forming heterodimers with either the agonist Bax or the antagonist Bcl-2, the mitochondrial damage leading to apoptosis.

miR-BART7-3p has been hypothesized to play a role in tumor growth and invasion through the suppression of phosphatase and tensin homolog (PTEN) protein and others against decapentaplegic homolog 7 (SMAD7) [57, 58]. PTEN is one of the main tumor suppressor genes involved in the regulation of the cell cycle. SMAD7 is a transforming growth factor beta (TGF $\beta$ ) type 1 receptor antagonist. The SMAD7/ TGF $\beta$ interaction blocks IL$1 R / T L R$ signaling, which subsequently reduces the expression of pro-inflammatory genes. SMAD7 production is induced by TGF $\beta$, but also by epidermal growth factor, IFN- $\gamma$ and TNF- $\alpha$. Therefore, SMAD7 may also prevent metastasis in $\mathrm{EBV}+$ gastric cancer. Moreover, by 
Table 2 miR-BART targets and their functions in different cancers

\begin{tabular}{|c|c|c|c|c|}
\hline miR-BART & Target & Function & Disease & Reference \\
\hline miR-BART13-3p & Tumor suppressor AB12 & EMT & $\mathrm{HL}, \mathrm{NPC}$ & [32] \\
\hline mR-BART19-3p & Unknown & - & $\mathrm{HL}, \mathrm{NPC}, \mathrm{ENKL}$ & [23] \\
\hline miR-BART2-5P & MICB BALF5 & $\begin{array}{l}\text { Ligand for activator NKG2D NK receptor } \\
\text { RNA polymerase II and B-cell receptor } \\
\text { NFKB activation }\end{array}$ & GC, NPC HL, ENKL & [34-38] \\
\hline miR-BART7-3p & $\begin{array}{l}\text { phosphatase and tensin } \\
\text { homolog (PTEN) mothers } \\
\text { against decapentaplegic } \\
\text { homolog } 7 \text { (SMAD7) }\end{array}$ & Tumor suppressor, pro- inflammatory, stem-like & GC & {$[56-58]$} \\
\hline miR-BART4-5p & $\begin{array}{l}\text { BH3 interacting-domain } \\
\text { death agonist (Bid) }\end{array}$ & Pro-apoptotic protein & GC & {$[56]$} \\
\hline miR-BART17-5p & $\begin{array}{l}\text { DNA transcription factor } \\
\text { Kruppel-like factor } 2 \text { (KLF2) }\end{array}$ & Energy metabolism inflammation & GC & {$[59,60]$} \\
\hline $\begin{array}{l}\text { miR-BART I,II } \\
\text { cluster }\end{array}$ & $\begin{array}{l}\text { bcl2-interacting mediators } \\
\text { of cell death (Bim) }\end{array}$ & Pro-apoptotic protein Autophagy & GC & [61] \\
\hline miR-BART3-3p & TP53 & tumor suppressor & GC & [62] \\
\hline miR-BART5- 3p & TP53 PIAS3 & tumor suppressor inhibitor of pSTAT and pDL-1 & GC & {$[44,63]$} \\
\hline miR-BART15-5p & $\begin{array}{l}\text { NLRP3 inflammasome } \\
\text { BRUCE and TAX1BP1 }\end{array}$ & $\begin{array}{l}\text { pro-inflammatory cytokines such as } \\
\text { IL-1 } \beta \text { and IL-18, gasdermin D- mediated } \\
\text { pyroptotic cell death apoptosis }\end{array}$ & GC & [64-66] \\
\hline
\end{tabular}

EMT Epithelial-mesenchymal transition; ENKL Nasal NK7T-cell lymphoma; GC Gastric cancer; HL Hodgkin lymphoma; NPC Nasopharyngeal carcinoma

inducing a cancer stem cell-like alteration, SMAD7 enables cells to better resist chemoradiotherapy. Gold nanoparticles carrying an anti-miR-BART7-3p antibody reduced tumor growth in an animal model, suggesting that this miRNA has a crucial role in epithelial cancer [67].

miR-BART17-5p is expressed in gastric cancer tissue $[59,60]$ and in EBV+ gastric cancer cell lines [60]. High miR-BART17-5p serum levels were found in NPC patients in association with progression and recurrence of the tumor [68-70]. In NPC, LMP1 is the main target of miR-BART17-5p [71]. However, since LMP1 expression is abrogated in EBV-positive gastric cancer, the main effect of miR-BART17-5p occurs on the transcription factor Kruppel-like factor 2 (KLF2) [59]. KLF2 negatively regulates energy metabolism of tumor cells and inflammation; thus, miRBART action on KLF2 positively favors gastric cancer cell migration and anchorage-independent growth.

Additionally, several miR-BARTs from clusters I and II were found to downregulate the expression of bcl2interacting mediators of cell death (BIM) [61]. A previous study reported an association between reduction of BIM and progression of gastric cancer [72]. BIM was found to play a key role in gastric cancer by reducing autophagy, an adaptive response to apoptosis. Autophagy is a common response to starvation, which prolongs cell survival through the degradation and recycling of cellular macromolecules to provide energy and molecular precursors [73]. Other miR- BARTs (mainly miRBART3-3p, miR-BART5-5p and miR-BART2-5p) were encoded by EBV to support host immune escape of gastric tumor cells.
In gastric cancer, miR-BART3-3p was found to inhibit tumor infiltration by NK cells and macrophages, by altering the senescence (temporary or permanent cell cycle arrest)-associated secretory phenotype (SASP) [62]. It seems that miR-BART3-3p directly targets the tumor suppressor gene TP53 and the TP53 target, p21, to produce this effect.

miR-BART5-5p also targets TP53, and thus promotes cell survival [74]. Of interest, it also directly targets PIAS3, an inhibitor of the activated pSTAT3 protein [59]. PSTAT3 migrates to the nucleus where it induces the transcription of several genes in gastric cancer. Since the PD-L1 gene promoter contains sequences for STAT3 binding, the result is of interest because gastric cancers EBV-positive and those having a high microsatellite instability are the best tumor candidate for immunological therapies (i.e. immune PD-1/PDL-1 checkpoint blockade) [44].

Another way to reduce immune surveillance is to release some miR-BARTs through exosomes.

Some miR-BARTs were found to be highly enriched in exosomes of EBV+ gastric cancer cell lines [75]. It is important to note that only some miR-BARTs are released in exosomes [76]. Several ways for miRNAs to enter vesicles have been hypothesized [77, 78]. Among the frequent miR-BART in exosomes of gastric cancer is miRBART15-5p. This miR-BART regulates NLRP3 (NOD). NLRP3 is an intracellular sensor of danger that activates the NLRP3 inflammasome, leading to the release of proinflammatory cytokines (e.g. IL-1 $\beta$ and IL-18) and to gasdermin D-mediated pyroptotic cell death, which 
actives the innate immune response $[65,66]$. Therefore, miBART15-5p limits inflammation to promote EBV infection [78]. Moreover, miR-BART15-5p may also have a role in the induction of apoptosis by targeting two inhibitory proteins of apoptosis, BRUCE and TAX1BP1 [64]. Therefore, it leads to death of tumor cells but also of cells around the tumor, including immune cells, through the release of exosomes.

\section{Conclusions}

Interactions between EBV miR-BARTs and Hodgkin lymphoma and gastric cancer are still poorly understood. Nonetheless, in recent years, the importance of these molecules in cancer has been acknowledged. Of special interest is the regulation of their expression in different EBV-related malignancies. Some miR-BARTs are released through exosomes into the tumor microenvironment. The mechanism to sustain miR-BART expression and release in exosomes is unclear.

Hypermethylation is not involved. The best hypothesis is that they are regulated by RNA targets in the tumor cells. Modification of the tumor microenvironment through miR-BARTs transported by exosomes is important mainly for the effect on the host immune response and a better understanding of these biological mechanisms may be helpful for the development of innovative therapies. miR-BARTs are released by tumor cells into blood in a stable form, and some of them are abundant in EBV-associated malignancies. Some miR-BARTs have already been found to be useful biomarkers for the diagnosis of the first occurrence or recurrence of a malignancy. Several studies are currently investigating which miR-BARTs are associated with specific EBV+ malignancies and may have clinical utility. Altogether, this new information is important for the development of novel diagnostic and prognostic biomarkers and for identifying targets for the development of more effective therapies, including those that boost host immunity.

\footnotetext{
Abbreviations

EBV: Epstein-barr virus; miRNA: Micro RNA; BART: BamHl fragment A rightward transcript; $\mathrm{BHRF} 1$ : BamHI fragment $\mathrm{H}$ rightward open reading frame 1; HL: Hodgkin lymphoma; GC: Gastric carcinoma cancer; HIV: Human immunodeficiency virus; CR2/CD21: Complement receptor type 2; EBNA1: EBV nuclear antigen 1; Lnc: Long noncoding RNAs; NPC: Nasopharyngeal cancer; Pol: POLYMERASE; IFN: Interferon; CXCL8: Chemokine 8; IRF: Interferon regulatory factor; NK: Natural killer cell; LMP: Latent membrane protein; NF-kB: Nuclear factor-kB; TAMs: Tumorassociated macrophages; PD-L: Programmed death ligand; IL: Interleukin; IgV: Immunoglobulin variable; TNF: Tumor necrosis factor; MHC: Major histocompatibility complex; MICB: MHC class I polypeptide-related sequence B; PTEN: Phosphatase and tensin homolog; Bid: Pro-apoptotic $\mathrm{BH} 3$ interacting-domain death agonist; SMAD7: Decapentaplegic homolog 7; TGFB: Transforming growth factor beta; KLF2: Transcription factor Kruppellike factor 2; BIM: Bcl2-interacting mediators of cell death; STAT: Signal transducer and activator of transcription; NLRP3: NOD-, LRR- and pyrin domain-containing protein 3; EMT: Epithelial-mesenchymal transition; ENKL: Nasal NK7T-cell lymphoma
}

Acknowledgements

"Not applicable".

Authors' contributions

All the authors declare that they have participated in writing the paper and approved the final version.

Funding

No funding

Availability of data and materials

"Not applicable".

Ethics approval and consent to participate

"Not applicable".

\section{Consent for publication}

"Not applicable".

\section{Competing interests}

There are no conflicts of interest in connection with this paper, and the material described is not under publication or consideration for publication elsewhere.

\section{Author details}

'Immunopathology and Cancer Biomarkers, Department of Translational Research, Centro di Riferimento Oncologico di Aviano (CRO), IRCCS, Aviano, PN, Italy. ${ }^{2}$ Medical Oncology and Cancer Prevention, Department of Medical Oncology, IRCCS, Centro di Riferimento Oncologico di Aviano (CRO), Aviano, PN, Italy. ${ }^{3}$ Department of Medicine, University of Udine, Udine, Italy. ${ }^{4}$ Gastroenterology, Department of Medical Oncology, Centro di Riferimento Oncologico di Aviano (CRO), IRCCS, Aviano, PN, Italy. ${ }^{5}$ Pathology, Department of Translational Research, Centro di Riferimento Oncologico di Aviano (CRO), Aviano, PN, Italy. ${ }^{6}$ Department of Medical, Surgical and Health Sciences, University of Trieste Medical School, Trieste, Italy. ${ }^{7}$ Pediatric Hematology and Oncology Unit, Oncology, Department, A.R.N.A.S. Ospedali Civico Di Cristina e Benfratelli, Palermo, PN, Italy. ${ }^{8}$ Nuclear Medicine Department, Humanitas Clinical and Research Hospital, Via Manzoni 56, 20089 Rozzano, Ml, Italy. ${ }^{9}$ Department of Pathology, San Bortolo Hospital, Vicenza, VI, Italy. ${ }^{10}$ Pediatric Hematology-Oncology, Azienda Ospedaliera Universitaria, Ospedale

Sant'Anna, Ferrara, FE, Italy. "1Pediatric Hemato-Oncology Clinic, Department of Women's and Children's Health, University of Padua, Institute of Paediatric Research Fondazione Città della Speranza, Padua, PD, Italy. ${ }^{12}$ Pediatric Radiotherapy Unit, Centro di Riferimento Oncologico di Aviano (CRO), IRCCS, Aviano, PN, Italy.

Received: 10 May 2020 Accepted: 11 June 2020

Published online: 23 June 2020

\section{References}

1. Khan G, Hashim MJ. Global burden of deaths from Epstein-Barr virus attributable malignancies 1990-2010. Infect Agents Cancer. 2014;9:38.

2. Shannon-Lowe C, Adland E, Bell Al, Delecluse H-J, Rickinson AB, Rowe M. Features distinguishing Epstein-Barr virus infections of epithelial cells and $B$ cells: viral genome expression, genome maintenance, and genome amplification. J Virol. 2009;83:7749-60.

3. Chen J, Sathiyamoorthy K, Zhang X, Schaller S, Perez White BE, Jardetzky TS, et al. Ephrin receptor A2 is a functional entry receptor for Epstein-Barr virus. Nat Microbiol. 2018:3:172-80.

4. Xiao J, Palefsky JM, Herrera R, Berline J, Tugizov SM. The Epstein-Barr virus BMRF-2 protein facilitates virus attachment to Oral epithelial cells. Virology. 2008:370:430-42.

5. Xiong D, Du Y, Wang H-B, Zhao B, Zhang H, Li Y, et al. Nonmuscle myosin heavy chain IIA mediates Epstein-Barr virus infection of nasopharyngeal epithelial cells. Proc Natl Acad Sci U S A. 2015;1 12:11036-41.

6. Fukayama M, Hayashi Y, Iwasaki Y, Chong J, Ooba T, Takizawa T, et al. Epstein-Barr virus- associated gastric carcinoma and Epstein-Barr virus infection of the stomach. Lab Investig. 1994;71:73-81.

7. Murata T, Okuno Y, Sato Y, Watanabe T, Kimura H. Oncogenesis of CAEBV revealed: intragenic deletions in the viral genome and leaky expression of lytic genes. Rev Med Virol. 2020;30:e2095. 
8. Pfeffer S, Zavolan M, Grässer FA, Chien M, Russo JJ, Ju J, et al. Identification of virus-encoded microRNAs. Science. 2004;304:734-6.

9. Fan C, Tang Y, Wang J, Xiong F, Guo C, Wang Y, et al. The emerging role of Epstein-Barr virus encoded microRNAs in nasopharyngeal carcinoma. J Cancer. 2018;9:2852-64.

10. Marquitz AR, Mathur A, Edwards RH, Raab-Traub N. Host gene expression is regulated by two types of noncoding RNAs transcribed from the EpsteinBarr virus BamHI a rightward transcript region. J Virol. 2015;89:11256-68.

11. Wang Y, Guo Z, Shu Y, Zhou H, Wang H, Zhang W. BART miRNAs: an unimaginable force in the development of nasopharyngeal carcinoma. Eur J Cancer Prev. 2017;26:144-50.

12. Smith PR, de Jesus $O$, Turner D, Hollyoake M, Karstegl CE, Griffin BE, et al. Structure and coding content of CST (BART) family RNAs of Epstein-Barr virus. J Virol. 2000;74:3082-92.

13. Verhoeven RJA, Tong S, Mok BW-Y, Liu J, He S, Zong J, et al. Epstein-barr Virus BART long non- coding RNAs function as epigenetic modulators in nasopharyngeal carcinoma. Front Oncol. 2019;9 [cited 2020 Apr 8]; Available from: https://www.ncbi.n/m.nih.gov/pmc/articles/PMC6817499/.

14. Kim DN, Lee SK. Biogenesis of Epstein-Barr virus microRNAs, vol. 365. New York: Molecular and Cellular Biochemistry; 2012. p. 203-10.

15. Sato A, et al. Clinicaloutcome of Epstein-Barr virus-positive diffuselarge B-cell lymphoma of the elderly in therituximab era. Cancer Sci. 2014;105(9):11705.

16. Jarrett RF, et al. Scotland andNewcastle epidemiology of Hodgkin DiseaseStudy group. Impact of tumor Epstein-Barr vi-rus status on presenting features and outcomein age-defined subgroups of patients withclassic Hodgkin lymphoma: a population-basedstudy. Blood. 2005; 106(7):2444-51.

17. Qiu J, Cosmopoulos K, Pegtel M, Hopmans E, Murray P, Middeldorp J, et al. A novel persistence associated EBV miRNA expression profile is disrupted in Neoplasia. Speck SH, editor. PLoS Pathog. 2011;7:e1002193.

18. Tsang CM, Lui WWY, Bruce JP, Pugh TJ, Lo KW. Translational genomics of nasopharyngeal cancer. Semin Cancer Biol. 2020;61:84-100.

19. Verhoeven RJA, Tong S, Zhang G, Zong J, Chen Y, Jin D-Y, et al. NF-KB signaling regulates expression of Epstein-Barr virus BART MicroRNAs and Long noncoding RNAs in nasopharyngeal carcinoma. J Virol. 2016;90:6475-88.

20. von Hoff L, Kärgel E, Franke V, McShane E, Schulz-Beiss KW, Patone G, et al Autocrine LTA signaling drives NF-KB and JAK-STAT activity and myeloid gene expression in Hodgkin lymphoma. Blood. 2019;133:1489-94.

21. Hinz M, Löser $P$, Mathas S, Krappmann D, Dörken B, Scheidereit C Constitutive NF-kappaB maintains high expression of a characteristic gene network, including CD40, CD86, and a set of antiapoptotic genes in Hodgkin/reed-Sternberg cells. Blood. 2001;97:2798-807.

22. Kilger $\mathrm{E}$, Kieser A, Baumann M, Hammerschmidt W. Epstein-Barr virusmediated B-cell proliferation is dependent upon latent membrane protein 1, which simulates an activated CD40 receptor. EMBO J. 1998;17:1700-9.

23. Sakamoto K, Sekizuka T, Uehara T, Hishima T, Mine S, Fukumoto H, et al. Next-generation sequencing of miRNAs in clinical samples of Epstein-Barr virus-associated B-cell lymphomas. Cancer Med. 2017:6:605-18.

24. Wu L, Wang J, Zhu D, Zhang S, Zhou X, Zhu W, et al. Circulating EpsteinBarr virus microRNA profile reveals novel biomarker for nasopharyngeal carcinoma diagnosis. Cancer Biomark. 2020;27:365-75.

25. Gao W, Wong T-S, Lv K-X, Zhang M-J, Tsang RK-Y, Chan JY-W. Detection of Epstein-Barr virus (EBV)-encoded microRNAs in plasma of patients with nasopharyngeal carcinoma. Head Neck-J Sci Spec Head Neck. 2019;41:780-92.

26. Motsch N, Alles J, Imig J, Zhu J, Barth S, Reineke T, et al. MicroRNA profiling of Epstein-Barr virus-associated NKT-cell lymphomas by deep sequencing. PLoS One. 2012;7:e42193.

27. Higuchi H, Yamakawa N, Imadome K-I, Yahata T, Kotaki R, Ogata J, et al. Role of exosomes as a proinflammatory mediator in the development of EBVassociated lymphoma. Blood. 2018;131:2552-67.

28. Pegtel DM, Cosmopoulos K, Thorley-Lawson DA, van Eijndhoven MAJ, Hopmans ES, Lindenberg JL, et al. Functional delivery of viral miRNAs via exosomes. Proc Natl Acad Sci U S A. 2010;107:6328-33.

29. De Re V, Caggiari L, Repetto O, Mussolin L, Mascarin M. Classical Hodgkin's lymphoma in the era of immune checkpoint inhibition. J Clin Med. 2019; 8(10):1596

30. Locati M, Curtale G, Mantovani A. Diversity, mechanisms, and significance of macrophage plasticity. Annu Rev Pathol. 2020;15:123-47.

31. Ramayanti $O$, Verkuijlen SAWM, Novianti P, Scheepbouwer C, Misovic B, Koppers-Lalic D, et al. Vesicle-bound EBV-BART13-3p miRNA in circulation distinguishes nasopharyngeal from other head and neck cancer and asymptomatic EBV-infections. Int J Cancer. 2019;144:2555-66.

32. Huang J, Qin Y, Yang C, Wan C, Dai X, Sun Y, et al. Downregulation of ABI2 expression by EBV- miR-BART13-3p induces epithelial-mesenchymal transition of nasopharyngeal carcinoma cells through upregulation of cJUN/SLUG signaling. Aging (Albany NY). 2020;12:340-58.

33. Chen Y, Fachko D, Ivanov NS, Skinner CM, Skalsky RL. Epstein-Barr virus microRNAs regulate $B$ cell receptor signal transduction and lytic reactivation. Lin Z, editor. PLoS Pathog. 2019;15:e1007535.

34. van Eijndhoven MAJ, Zijlstra JM, Groenewegen NJ, Drees EEE, van Niele S, Baglio SR, et al. Plasma vesicle miRNAs for therapy response monitoring in Hodgkin lymphoma patients. JCI Insight. 2016;1(19):e89631.

35. Barth S, Pfuhl T, Mamiani A, Ehses $C$, Roemer K, Kremmer E, et al. EpsteinBarr virus-encoded microRNA miR-BART2 down-regulates the viral DNA polymerase BALF5. Nucleic Acids Res. 2008;36:666-75.

36. Jiang C, Chen J, Xie S, Zhang L, Xiang Y, Lung M, et al. Evaluation of circulating EBV microRNA BART2-5p in facilitating early detection and screening of nasopharyngeal carcinoma: tumor markers and signatures. Int $J$ Cancer. 2018;143:3209-17.

37. Komabayashi Y, Kishibe K, Nagato T, Ueda S, Takahara M, Harabuchi Y. Circulating Epstein-Barr virus-encoded micro-RNAs as potential biomarkers for nasal natural killer/T-cell lymphoma. Hematol Oncol. 2017;35:655-63.

38. Nachmani D, Stern-Ginossar N, Sarid R, Mandelboim O. Diverseherpesvirus microRNAs target the stress-induced immune ligand MICB to escape recognition by natural killer cells. Cell Host Microbe. 2009;5:376-85.

39. Uemura $Y$, Isobe $Y$, Uchida A, Asano J, Nishio $Y$, Sakai $H$, et al. Expression of activating natural killer-cell receptors is a hallmark of the innate-like T-cell neoplasm in peripheral T-cell lymphomas. Cancer Sci. 2018;109:1254-62.

40. Alessandrini L, Manchi M, De Re V, Dolcetti R, Canzonieri V. Proposed molecular and miRNA classification of gastric Cancer. Int J Mol Sci. 2018;19.

41. Cancer Genome Atlas Research Network. Comprehensive molecular characterization ofgastric adenocarcinoma. Nature. 2014;513:202-9.

42. Cristescu R, Lee J, Nebozhyn M, Kim K-M, Ting JC, Wong SS, et al. Molecular analysis ofgastric cancer identifies subtypes associated with distinct clinical outcomes. Nat Med. 2015;21:449-56.

43. Strong MJ, Xu G, Coco J, Baribault C, Vinay DS, Lacey MR, et al. Differences in gastric carcinoma microenvironment stratify according to EBV infection intensity: implications for possible immune adjuvant therapy. PLoS Pathog. 2013;9:e1003341.

44. Gu L, Chen M, Guo D, Zhu H, Zhang W, Pan J, et al. PD-L1 and gastric cancer prognosis: a systematic review and meta-analysis. PLoS One. 2017;12: e0182692.

45. Sokolova O, Naumann M. NF-kB signaling in Gastric cancer. Toxins (Basel). 2017;9(4):119.

46. Edwards RH, Marquitz AR, Raab-Traub N. Epstein-Barr virus BART microRNAs are produced from a large intron prior to splicing. J Virol. 2008:82:9094-106.

47. Zhang X, Ye Y, Fu M, Zheng B, Qiu Q, Huang Z. Implication of viral microRNAs in the genesis and diagnosis of Epstein-Barr virus-associated tumors (review). Oncol Lett. 2019;18:3433-42.

48. Lung RW-M, Tong JH-M, Sung Y-M, Leung P-S, Ng DC-H, Chau S-L, et al. Modulation of LMP2A expression by a newly identified Epstein-Barr virusencoded MicroRNA miR-BART22. Neoplasia. 2009;11:1174-U89.

49. Lo AKF, To KF, Lo KW, Lung RWM, Hui JWY, Liao G, et al. Modulation of LMP1 protein expression by EBV-encoded microRNAs. Proc Natl Acad Sci U S A. 2007:104:16164-9.

50. Pandya D, Mariani M, He S, Andreoli M, Spennato M, Dowell-Martino C, et al. Epstein-Barr virus MicroRNA expression increases aggressiveness of solid malignancies. PLoS One. 2015;10:e0136058.

51. Jung Y-J, Choi H, Kim H, Lee SK. MicroRNA miR-BART20-5p stabilizes Epstein-Barr virus latency by directly targeting BZLF1 and BRLF1. J Virol. 2014;88:9027-37.

52. Ramakrishnan R, Donahue H, Garcia D, Tan J, Shimizu N, Rice AP, et al. Epstein-Barr virus BART9 miRNA modulates LMP1 levels and affects growth rate of nasal NK T cell lymphomas. PLoS One. 2011;6:e27271.

53. Hooykaas MJG, Kruse E, Wiertz EJHJ, Lebbink RJ. Comprehensive profiling offunctional Epstein-Barr virus miRNA expression in human cell lines. BMC Genomics. 2016;17:644

54. Ghasemi F, Gameiro SF, Tessier TM, Maciver AH, Mymryk JS. High levels of class IMajor histocompatibility complex mRNA are present in Epstein-Barr virus-associated gastric adenocarcinomas. Cells. 2020:9(2):499. 
55. Liu X, Liu J, Qiu H, Kong P, Chen S, Li W, et al. Prognostic significance of Epstein-Barr virus infection in gastric cancer: a meta-analysis. BMC Cancer. 2015;15:782.

56. Shinozaki-Ushiku A, Kunita A, Isogai M, Hibiya T, Ushiku T, Takada K, et al. Profiling of virus- encoded MicroRNAs in Epstein-Barr virus-associated gastric carcinoma and their roles in gastric carcinogenesis. J Virol. 2015;89: 5581-91.

57. Cai L, Long Y, Chong T, Cai W, Tsang CM, Zhou X, et al. EBV-miR-BART7-3p imposes Stemness in nasopharyngeal carcinoma cells by suppressing SMAD7. Front Genet. 2019;10:939.

58. Cai L-M, Lyu X-M, Luo W-R, Cui X-F, Ye Y-F, Yuan C-C, et al. EBV-miRBART7-3p promotes the EMT and metastasis of nasopharyngeal carcinoma cells by suppressing the tumor suppressor PTEN. Oncogene. 2015;34:2156-66.

59. Yoon JH, Min K, Lee SK. Epstein-Barr virus miR-BART17-5p promotes migration and Anchorage- independent growth by targeting Kruppel-like factor 2 in gastric Cancer. Microorganisms. 2020;8(2):258.

60. Treece AL, Duncan DL, Tang W, Elmore S, Morgan DR, Dominguez RL, et al. Gastric adenocarcinoma microRNA profiles in fixed tissue and in plasma reveal cancer-associated and Epstein-Barr virus-related expression patterns. Lab Investig. 2016;96:661-71.

61. Marquitz AR, Mathur A, Nam CS, Raab-Traub N. The Epstein-Barr virus BART microRNAs target the pro-apoptotic protein Bim. Virology. 2011;412:392400.

62. Wang J, Zheng X, Qin Z, Wei L, Lu Y, Peng Q, et al. Epstein-Barr virus miRBART3-3p promotes tumorigenesis by regulating the senescence pathway in gastric cancer. J Biol Chem. 2019;294:4854-66.

63. Yoon CJ, Chang MS, Kim DH, Kim W, Koo BK, Yun S-C, et al. Epstein-Barr virusencoded miR- BART5-5p upregulates PD-L1 through PIAS3/pSTAT3 modulation, worsening clinical outcomesof PD-L1-positive gastric carcinomas. Gastric Cancer. 2020; https://doi.org/10.1007/s10120-020-01059-3.

64. Choi H, Lee SK. TAX1BP1 downregulation by EBV-miR-BART15-3p enhances chemosensitivity of gastric cancer cells to 5-FU. Arch Virol. 2017;162:369-77.

65. Swanson KV, Deng M, Ting JP-Y. The NLRP3 inflammasome: molecular activation and regulation to therapeutics. Nat Rev Immunol. 2019;19:477-89.

66. Schroder K, Tschopp J. The inflammasomes. Cell. 2010;140:821-32.

67. Cai L, Li J, Zhang X, Lu Y, Wang J, Lyu X, et al. Gold nano-particles (AuNPs) carrying anti-EBV- miR-BART7-3p inhibit growth of EBV-positive nasopharyngeal carcinoma. Oncotarget. 2015;6:7838-50.

68. Hirai N, Wakisaka N, Kondo S, Aga M, Moriyama-Kita M, Ueno T, et al. Potential interest inCirculating miR-BART17-5p as a post-treatment biomarker for prediction of recurrence in Epstein- Barr virus-related nasopharyngeal carcinoma. PLoS One. 2016;11:e0163609.

69. Gourzones C, Ferrand F-R, Amiel C, Vérillaud B, Barat A, Guérin M, et al. Consistent high concentration of the viral microRNA BART17 in plasma samples from nasopharyngeal carcinoma patients--evidence of nonexosomal transport. Virol J. 2013;10:119.

70. Zheng X-H, Lu L-X, Cui C, Chen M-Y, Li X-Z, Jia W-H. Epstein-Barr virus mirbart1-5p detection via nasopharyngeal brush sampling is effective for diagnosing nasopharyngeal carcinoma. Oncotarget. 2016;7:4972-80.

71. Riley KJ, Rabinowitz GS, Yario TA, Luna JM, Darnell RB, Steitz JA. EBV andhuman microRNAs co- target oncogenic and apoptotic viral and human genes during latency. EMBO J. 2012;31:2207-21.

72. Yano $\mathrm{T}$, Ito K, Fukamachi $\mathrm{H}$, Chi X-Z, Wee $\mathrm{H}$-J, Inoue $\mathrm{K}$, et al. The RUNX3 tumor suppressor upregulates Bim in gastric epithelial cells undergoing transforming growth factor beta-induced apoptosis. Mol Cell Biol. 2006;26: 4474-88.

73. Kong $P$, Zhu X, Geng Q, Xia L, Sun X, Chen Y, et al. The microRNA-423-3pBim Axis promotes Cancer progression and activates oncogenic autophagy in gastric Cancer. Mol Ther. 2017;25:1027-37.

74. Zheng X, Wang J, Wei L, Peng Q, Gao Y, Fu Y, et al. Epstein-Barr virus MicroRNA miR-BART5-3p inhibits p53 expression. J Virol. 2018;92(23): e01022-18.

75. Fu M, Gu J, Jiang P, Qian H, Xu W, Zhang X. Exosomes in gastric cancer: roles, mechanisms, and applications. Mol Cancer. 2019;18:41.

76. Gallo A, Vella S, Miele M, Timoneri F, Di Bella M, Bosi S, et al. Global profiling of viral and cellular non-coding RNAs in Epstein-Barr virus-induced lymphoblastoid cell lines and released exosome cargos. Cancer Lett. 2017; 388:334-43.
77. Choi H, Lee H, Kim SR, Gho YS, Lee SK. Epstein-Barr virus-encoded microRNA BART15-3p promotes cell apoptosis partially by targeting BRUCE. J Virol. 2013:87:8135-44.

78. Haneklaus M, Gerlic M, Kurowska-Stolarska M, Rainey A-A, Pich D, Mclnnes IB, et al. Cutting edge: miR-223 and EBV miR-BART15 regulate the NLRP3 inflammasome and IL-1 $\beta$ production. J Immunol. 2012;189:3795-9.

\section{Publisher's Note}

Springer Nature remains neutral with regard to jurisdictional claims in published maps and institutional affiliations.

\section{Ready to submit your research? Choose BMC and benefit from:}

- fast, convenient online submission

- thorough peer review by experienced researchers in your field

- rapid publication on acceptance

- support for research data, including large and complex data types

- gold Open Access which fosters wider collaboration and increased citations

- maximum visibility for your research: over $100 \mathrm{M}$ website views per year

At BMC, research is always in progress.

Learn more biomedcentral.com/submissions 